\title{
Using expletive insertion to pursue and sanction in interaction
}

\author{
Elliott M. Hoey $^{1,2}$ (D) | Paul Hömke ${ }^{3}$ | Emma Löfgren ${ }^{4}$ | \\ Tayo Neumann $^{4}$ | William L. Schuerman ${ }^{5}$ | Kobin H. Kendrick ${ }^{6}$
}

${ }^{1}$ University of Basel, Basel, Switzerland

${ }^{2}$ University of Siegen, Siegen, Germany

${ }^{3}$ Radboud University, Nijmegen, The Netherlands

${ }^{4}$ Max Planck Institute for Psycholinguistics, Nijmegen, The Netherlands

${ }^{5}$ University of California-San Francisco, San Francisco, CA, USA

${ }^{6}$ University of York, York, UK

\section{Correspondence}

Elliott M. Hoey, University of Basel, Maiengasse 51, 4056 Basel, Switzerland.

Email: elliottmichael.hoey@unibas.ch

\section{Funding information}

This research was supported by the Netherlands Organisation for Scientific Research through Rubicon grant \#44617010 for EMH and Rubicon grant \#P0522734 for WS.

\begin{abstract}
This article uses conversation analysis to examine constructions like who the fuck is that-sequence-initiating actions into which an expletive like the fuck has been inserted. We describe how this turn-constructional practice fits into and constitutes a recurrent sequence of escalating actions. In this sequence, it is used to pursue an adequate response after an inadequate one was given, and sanction the recipient for that inadequate response. Our analysis contributes to sociolinguistic studies of swearing by offering an account of swearing as a resource for social action.
\end{abstract}

\section{K E Y W O R D S}

conversation analysis, escalation, response pursuit, swearing, upgrading

\section{1 | INTRODUCTION}

Swearing is an activity normatively restricted to particular conditions of use and categories of users, and people work to uphold and enforce those restrictions (Anderson \& Trudgill, 2007). These norms are institutionalized in legal decisions, religious regulations, and school policies that restrict forms of speech deemed discriminatory, obscene, offensive, etc. They are also embedded in language itself, observed in the various processes for deforming swear words (abbreviating fuck as eff) and the conventionalization of euphemisms (fudge for fuck). Participants in everyday interactions use these norms, tool. For instance, parents may admonish their child when they curse. Normative restrictions on who can curse and under what circumstances provide for recognizing the child's behavior as a sanctionable departure from the norm (see Heritage, 1984). Or take self-admonishments, like in Extract 1. Here, 
Heather complains to her friend Kelly about her coursework. She uses the phrase fuck my life (line 3) and then censors herself for swearing. ${ }^{1}$

(1) RCE28_1945_researcher-generated/UK

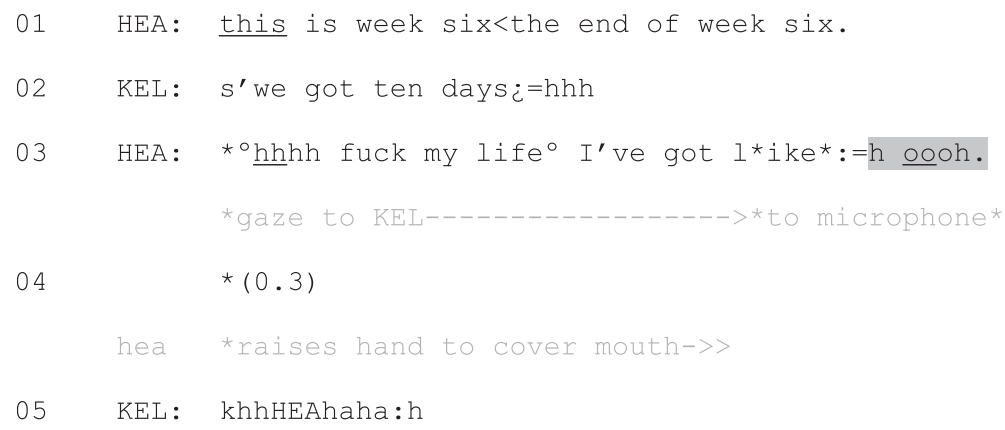

After fuck my life, Heather continues with I've got like, which is hearably a continuation of her complaint. She does not complete this turn, though. Instead, she cuts it off while glancing to the microphone on the table and producing an oooh response cry (line 3; Goffman, 1978). These behaviors locate a cause for her cutoff - the recording equipment — and display a 'realization' of something in relation to it. What was realized is clarified in her subsequent behavior. She covers her mouth with her hand (lines 4-5), embodying the suppression of speech. Given the proximity of her mouth-covering to fuck my life, Heather exhibits that phrase as something which should not have been produced. By censoring its production post hoc, she treats it as unsuitable for the setting. So while ordinarily she might utter fuck my life, she acknowledges the unordinariness of their circumstances and treats that phrase as sanctionably inappropriate.

Normative constraints on swearing give it a special status. In this paper we are interested in how that special status gets used as a resource for action in social interactions. We focus on turns such as who the fuck is that, sequence-initiating actions (Schegloff \& Sacks, 1973) into which grammatically optional expletives (Mackenzie, 2019) are inserted (Schegloff, 2013). The linguistic optionality of expletives suggests that they do discriminable work for interactants, which we aim to specify using conversation analysis (CA).

In this article, we argue that the practice of expletive insertion in a sequence-initiating action occurs in a particular sequential environment (detailed below), where it serves to pursue a response while also sanctioning the recipient. This analysis contributes to sociolinguistics the first in-depth examination of a particular swearing construction using CA. This technical account of a turn-constructional operation, as we will discuss, bears on our understanding of the organization of pursuits and has implications for processes of indexicality.

\section{BACKGROUND}

Though 'swearing' resists precise definition (e.g. Ljung, 2011), for our purposes it refers to various linguistic taboos: profanity, expletives, vulgarity, imprecations, etc. Such language is commonly related to religion, disease, sex, and bodily excretions (Napoli \& Hoeksema, 2009). These themes are not themselves taboo; rather, what is taboo is certain ways that they are invoked and used (Anderson \& Trudgill, 2007). Swearing may be literal and denotative (they fucked), but is more commonly nonliteral and connotative (I feel like shit). Its ubiquity across ages, domains, 
and languages (Jay, 2009; Ljung, 2011; McEnery, 2006) indicates its usefulness. Researchers have argued that speakers can use swearing to express solidarity, catharsis, and aggression (Wajnryb, 2005); for emotion, humor, and emphasis (Stapleton, 2010); and in ways oriented to both politeness and impoliteness (Dynel, 2012). Generally, then, it has been argued that swearing serves social and emotional aims that are not as easily or effectively achieved through non-taboo words.

Some of these social and emotional aims have been examined in CA, which has focused primarily on improprieties (the tactless, impolitic, coarse, etc.). Speakers may suppress or obscure improprieties (e.g. through devoicing or laughter), thereby orienting to their transgressive status in the very act of transgression (Schegloff, 2003). This renders such speech as not-quite-said (Jefferson, 1985) and potentially delicate (Lerner, 2013). Normative restrictions on swearing are apparent in institutional settings. In live broadcast interviews, orientations to swearing as 'gaffes' and 'slips' reflexively constitute institutional prohibitions on such language (Butler \& Fitzgerald, 2011). Restrictions around improprieties also let participants manage intimate-distant relationships (Korobov \& Laplante, 2013; Pomerantz \& Mandelbaum, 2005). An impropriety proposes a fleeting intimacy, which, if forwarded (e.g. through laughter and another impropriety), ratifies that proposal and co-implicates participants in the transgression (Jefferson, Sacks, \& Schegloff, 1987).

Taboo words show remarkable grammatical versatility (Napoli \& Hoeksema, 2009). In English, they may appear as exclamations (fuck!), verbs (are you shitting me), and nouns (give a fuck). In such cases, omitting these words results in ungrammatical utterances. We set aside this kind of swearing and instead focus on 'expletives' — grammatical elements devoid of denotational content, whose omission does not affect grammatical acceptability (see Mackenzie, 2019, p. 57).

Common among expletives in English are 'emphatic intensifiers' like fucking and goddamn. These routinely precede and modify nouns (put the fucking thing down), adjectives (that's fucking weird), verbs (tell him to fuckin hit the road), and some adverbs (fucking obviously). Their unique linguistic properties have been recognized since Bopp (1971), who classified them as 'quasi-adjectives' and 'quasi-adverbs'. Other common expletives in English of the type the fuck/hell/heck/devil/etc. may appear after some wh-words (where the fuck are you) and in phrasal verb constructions (get the hell out of here). The insertion of such expletives has attracted attention since Pesetsky's (1987) account of wh-movement, and also has been examined in constructions like beat the hell out of and get the hell out of, which, while pragmatically similar, in fact exhibit distinct syntactic and semantic properties (Hoeksema \& Napoli, 2008).

Investigations of expletives suggest that the conveyance of emotional intensity is key (Jay, 2009). That is, expletive insertion seems more associated with social and psychological matters than with a given construction's grammatical particulars. The importance of these factors is indirectly observed in the relative preponderance of sociocultural and psycholinguistic research on taboo language compared to more structural linguistic studies (Allan, 2018; Jay \& Janschewitz, 2008; though see Majid, 2012; Mackenzie, 2019). Indeed, studies of expletives recognize emotion as central to their meaning and function. Take for example the insertion of the hell. Pesetsky (1987, p. 111) observed that, 'the whole point of uttering a question like What the hell did you read that in? is to express surprise in the answer'. Others have echoed this sentiment: the hell 'conveys a presupposition that the speaker has a negative attitude' (Dikken \& Giannakidou, 2002, p. 43), and shows 'surprise or indignation' (Polinsky, 2007, p. 259). Similar descriptions apply to emphatic intensifiers: the 'function of the expletive fucking is to indicate the speaker's emotionally charged emphasis' (Mackenzie, 2019, p. 78), and the 'general meaning of such items is to indicate some sort of disapproval' (Bopp, 1971, p. 66). 


\subsection{The current study}

We analyze swearing-specifically, expletive insertion in sequence-initiating actions-using conversation analysis (see Hoey \& Kendrick, 2018; Sidnell \& Stivers, 2013). CA emphasizes the sequentiality of social action in actual episodes of interaction and offers a method for describing what speakers do with swearing.

As prior studies suggest, expletive insertion commonly expresses something like 'surprise' or 'negative attitude'. While not incorrect, these descriptions are limited. As generic, decontextualized formulations of expletives' meaning or function, they necessarily leech expletives of the very situational particulars that provide them their determinate sense (see Garfinkel \& Sacks, 1970). We understand participants as in the first instance accountable for the actions they do and are seen doing (Garfinkel, 1967; Schegloff, 1995). Analyses must therefore be answerable to that level of detail (Schegloff, 1992a). So while 'negative attitude' approximates an expletive's meaning, it remains disconnected from the practical relevancies of situated action to which expletive insertion is addressed.

We seek to overcome these limitations by using recordings of naturally occurring interactions, which preserve the contextual details that participants use to make sense of everyday language, and by grounding analyses in participants' observable orientations to the phenomenon. This amounts to considerations of where expletives occur in a course of action (position), how participants design their conduct (composition), and what gets accomplished through the particularities of position and composition (action). Our analysis thus builds on prior work by focusing on how expletive insertion contributes to the implementation of specific actions in social interactions. This article also contributes to $\mathrm{CA}$ research on swearing, which remains relatively underdeveloped, by offering the first sustained analysis of one interactional practice.

CA's analytic commitments entail setting aside matters that have occupied other discourse-oriented studies, such as sociolinguistic categories (McEnery \& Love, 2018), (im)politeness (Dynel, 2012), and indexical meanings (Christie, 2013). Instead of analyzing along such dimensions - therefore presuming their importance for a given interaction (Schegloff, 1992a)—we concern ourselves with participants' observable orientations to swearing. This is done not to discount other studies, but to ground the analysis first in the details of situated conduct. We also do not address expletives' grammatical properties (e.g. Napoli \& Hoeksema, 2009). We contend that the practical issue is deciding between two alternates: with the expletive or without. When we ask why people say who the fuck is that, we are asking how expletive insertion calibrates the action to the practical relevancies at hand and what this contributes to how those situations proceed.

In what follows, we describe our data and how we collected our cases of expletive insertion. We then begin the analysis by showing expletive insertion in initially positioned actions so as to then contrast it with expletive insertion in subsequently positioned actions. We argue that the sequential organization of the latter is more fundamental, and so we devote most of the analysis to explicating it. Briefly, we show that, in the context of some interactional difficulty, (a) a sequence-initiating action without an expletive is produced, creating an opportunity for the recipient to resolve the difficulty, but (b) the response is variously uncooperative, inappropriate, or inapposite, such that the difficulty persists, at which point (c) the sequence-initiating action is reissued with expletive insertion, an action that pursues a cooperative response and sanctions the recipient for willful or obtuse noncooperation. We elaborate on this sequential organization by addressing the interactional difficulties that it manages and its relation to 'escalation'. The analysis concludes by connecting expletive insertion in subsequently positioned actions to those in initially positioned actions. We discuss our findings in relation to the 'fit' between expletive insertion and sanctioning, to other practices for pursuit, and to their contribution to studies of swearing and indexicality. 


\section{METHODS}

This study emerged from an investigation of swearing in interaction, and is based on a collection of 33 cases of the practice under examination. The data are recordings of naturally occurring interactions primarily in US and UK English. ${ }^{2}$ Most cases $(n=24)$ are from researcher-generated recordings, which were collected with the consent of volunteer participants for the purpose of researching language usage. Specifically, these are from recordings made by US undergraduates $(n=13)$, Talkbank $(n=6)$, the authors' own research corpora $(n=2)$, the 'classic' CA recording Chicken Dinner $(n=2)$, and the Rossi Corpus of English $(n=1)$. Other cases are from participant-generated recordings uploaded to online sources YouTube and TikTok $(n=8)$ and from a reality television show in which a British family was continuously filmed at home $(n=1)$. All identifying information has been anonymized in the transcripts (except Extract 4, see footnote).

An initial scan of the research recordings resulted in 120 cases of swearing, generously understood by speakers as any instance of 'strong language'. Within these 120 cases, expletive insertion emerged as one prominent usage, and so we focused on that turn-constructional phenomenon in particular. We restricted ourselves to expletive insertion in sequence-initiating actions - that is, the first action in an adjacency pair, which makes conditionally relevant a determinate range of responses (Schegloff \& Sacks, 1973). As a result of this restriction, we discarded instances of responsive actions (fuck yeah), reported speech (I was like who the fuck am I supposed to wave to), embedded wh-clauses (I don't know what the hell happened), and word searches (then uh ${ }^{\circ}$ when the hell was $i t^{\circ}$ ).

With a preliminary analysis in place, we then collected cases from other sources, which allowed us to verify or refine our description of the practice. Because the practice was associated in our initial analysis with situations of discord and misalignment, we purposively sampled YouTube using search terms like 'UFO sighting' and 'street fight'. Eight cases were found this way. ${ }^{3}$ And finally, three cases were encountered serendipitously (i.e. not in a systematic data scan or targeted hunt for cases). This procedure resulted in a collection of 33 cases of expletive insertion in a sequence-initiating action.

The expletives observed in our collection were the fuck $(n=16)$, fuckin/fucking $(n=10)$, the hell $(n=2)$, in the hell $(n=1)$, the heck $(n=1)$, the $f: \because(n=1)$, goddamn $(n=1)$, and cazzo 'dick' (Italian; $n=1)$. These occurred in US English $(n=29)$, UK English $(n=3)$, and Italian $(n=1)$, mostly by male speakers $(n=28)$. Eight were produced by the same speaker within the same recording. The expletives appeared in imperative $(n=15)$ and interrogative $(n=18)$ utterances, either immediately after an interrogative pronoun ( $n=18$, where the fuck are you), immediately before the head of a noun phrase ( $n=8$, answer my fucking question), or in a more loosely defined adverbial position ( $n=7$, stay the fuck out of it). In two cases, an initial word was 'elided' such that the expletive appeared clause-initially (the fuck did that come from). We find no evidence that variation in syntactic position or linguistic form affects the practice's interactional import.

\section{4 | ANALYSIS}

Our collection shows two patterns whereby an expletive is inserted into a turn-at-talk. The expletive may appear in an initially positioned action, that is, at the very start of a course of action $(n=13)$. Alternatively, the expletive is inserted in a subsequently positioned action; the speaker reformulates their previous action and inserts into it an expletive $(n=20)$. We begin with expletive insertion in initial position and then contrast those with expletive insertion in subsequent position, which we argue is the home environment for this practice. 


\subsection{Expletive insertion in initially positioned actions}

Speakers may launch a course of action by designing their turn with expletive insertion. This is a mundanely recognizable practice of everyday language use in English. The case below shows how expletive insertion can be used to sanction a recipient. It shows a teenage daughter pulling a prank on her dad while recording it on her smartphone. The transcript begins as she enters the kitchen where he is cooking.

(2) TikTok_participant-generated/US

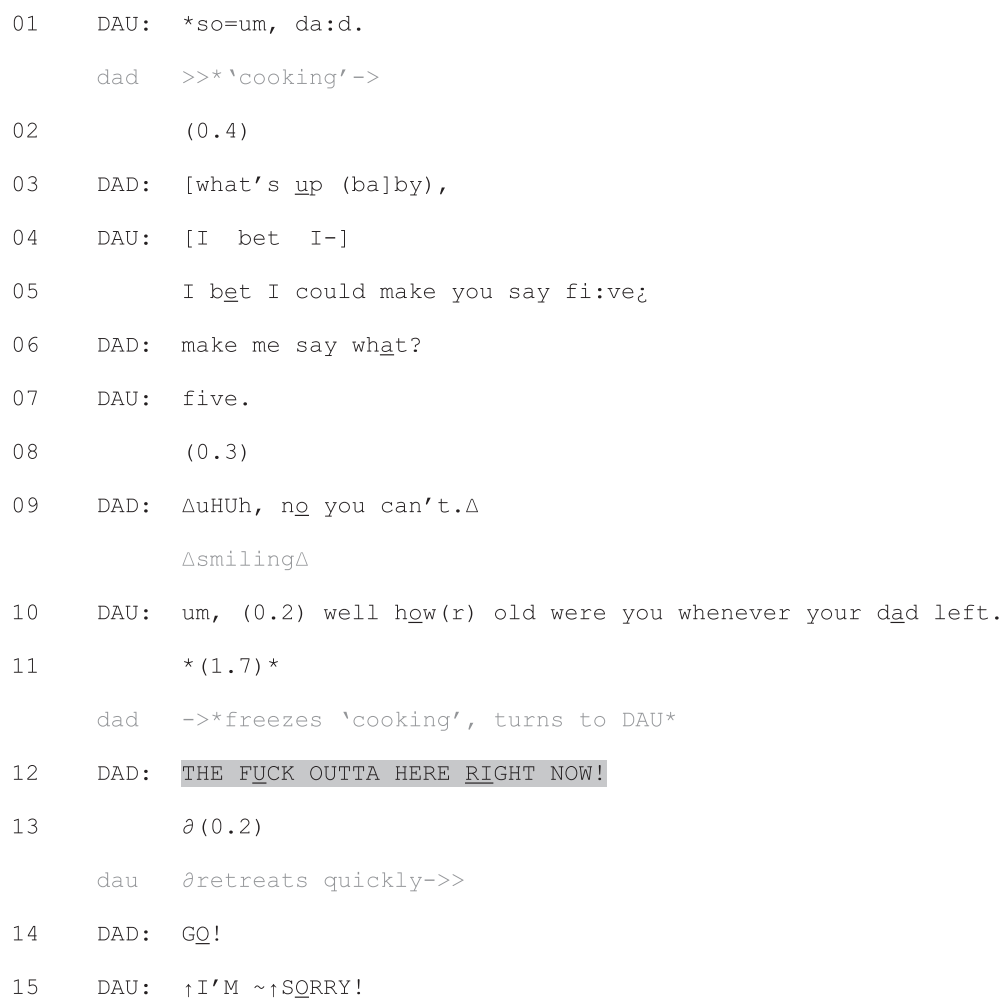

After gaining her dad's attention, the daughter wagers I bet I could make you say fi:ve (lines 1-5). This invites him into a 'joke' of sorts. In sequence organizational terms (Schegloff, 2007), she initiates a pre-sequence that projects a base sequence, in which a 'setup' turn will favor the word five appearing in his response. The dad's next-turn repair initiation (make me say what?; Schegloff, Jefferson, \& Sacks, 1977) is a tentative go-ahead, as it secures for him the word five (line 7), which he will now try to avoid saying. His more explicit go-ahead-scoffing laughter, a smile, and no you can't (line 9)_-allows his daughter to produce the projected setup turn. She begins with turn-initial well, which in this environment marks her prior action as preliminary to her coming one (Kim, 2013), followed by how $(r)$ old were you whenever your dad left. This makes relevant an 'age' response, which, for the joke to work, is mutually known to be 'five'.

The dad does not immediately respond and a gap develops (line 11). The subterfuge of the joke is apparently recognized at this time: he freezes his cooking movements and turns to her, his visibly 'stern' face contrasting with his smile from before. The light-hearted joke that he 
agreed to participate in has turned out to be a malicious trick. She has led him to acknowledge a hurtful detail of an already hurtful matter, with its injuriousness amplified by the act of recording, which embodies the forethought put into the prank and implicates its preservation and circulation.

The dad's reaction is not what was projected to occur there (an 'age' response), but a dramatically different action. Rather than responding, he initiates a course of action with a livid command: THE

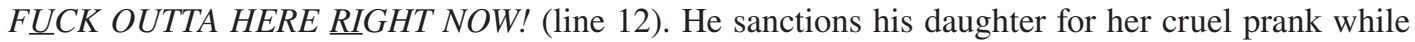
driving her away. Part of how this works is by reference to the dramatic contrast between the action expected and the action he produces instead — rather than 'playing along' he is now 'furiously driving her away'. He does this by designing his turn as hearably 'extreme'. The insertion of the fuck exhibits the action as 'upgraded' or 'heightened' in some manner; the shouting displays a greatly agitated affect as compared to his playful state just moments before; and the temporal adverbial RIGHT NOW imparts a sense of urgency. Moreover, the force of his action seems proportional to the cruelty of her prank (see Heritage, Raymond, \& Drew, 2019), as detectable in her immediate departure and quavering apology (line 15).

It seems clear enough that the fuck is part of sanctioning the daughter for her cruelty. The events leading up to that particular utterance action furnish the means for making sense of it. There are other cases, however, where expletive insertion occurs without the contextualizing benefit of prior talk. Below, some friends are having a barbecue in the park. One participant (Kimmy) is preparing the grill, and at the start of the transcript she is searching for a paper bag she had set aside to use as kindling (see Drew \& Kendrick, 2018).

(3) 011_LSIBBQ_1427_researcher-generated/US

01

$$
\star(3.7)
$$

kim *searching for bag, walking around picnic table->

KIM: *where the fuck is my little firestarting bag.

->*walking toward coparticipants, looking around table->

$(4.3)$

04

ALI: fire starting bag.=is *that it?

kim

$->*$ reaches to bag $->$

05

$(0.5)$

06
KIM:
$\underline{\mathrm{o}}: \mathrm{h}(\mathrm{p})-$ ?
(.)
(m) *yeah, that's it.

She begins walking toward her coparticipants and, evidently unsuccessful in her search, asks aloud where the fuck is my little firestarting bag? (line 2). This question initiates a course of action whereby a nearby participant identifies a candidate firestarting bag, which Kimmy then confirms as she retrieves it (lines 4-6). Kimmy's question is hearably complaining or expressing frustration, not only in 
its intonational contour but also in the use of expletive insertion. Unlike the previous case, there is no immediately prior talk to help contextualize her action. It is the very first action of this exchange, and so its design is the primary resource by which sense is made. Nevertheless, the mundane recognizability of this case suggests that participants are drawing upon some shared understanding in locating meaning in such utterances.

We suggest that the recognizability of expletive insertion in initially positioned actions trades on a shared understanding of expletive insertion in another sequential context, namely, in subsequently positioned actions. That is, the basis for hearing where the fuck is my little firestarting bag as expressing vexation or complaining is found in the sequential organization of expletive insertion in subsequently positioned actions. Prima facie evidence for this comes from the relative preponderance in our collection of expletive insertion in subsequent position $(n=20)$ compared to initial position $(n=13)$. Though our sampling was nonrandom, this distribution suggests that expletive insertion in subsequent position is more basic, and in initial position is more derived.

\section{2 | Expletive insertion in subsequently positioned actions}

Participants regularly use expletive insertion in a subsequent version of a prior action. This often takes the sequential organization of pursuits, as shown in the three-part sequence below. We will refer to these 'positions' throughout the paper.

\begin{tabular}{ll} 
Environment & $(($ some interactional difficulty between A and B $))$ \\
Position 1 & A: sequence-initiating action targeting the difficulty \\
Position 2 & B: responsive action that fails to resolve difficulty \\
Position 3 & A: same sequence-initiating action with expletive insertion \\
\hline
\end{tabular}

The environment is characterized by some interactional difficulty between participants, such as manifestations of resistance, noncooperation, misalignment, and miscalibration, among other possibilities. In this context, the speaker produces a sequence-initiating action in Position 1 , making conditionally relevant a response that could resolve the difficulty. The recipient's Position 2 response, however, does not do so, but is uncooperative, inappropriate, or otherwise fails to promote resolution of the problem. So, in Position 3 the speaker pursues an adequate response by reissuing their sequence-initiating action with expletive insertion. This sanctions the recipient for their uncooperative response while giving them another opportunity to produce an adequate one. In the transcripts, these positions are labeled (1>, 2>, 3>), after which the interaction continues.

We observe this sequential organization below. This interaction shows a road rage confrontation between a moped driver, whose helmet camera records the interaction, and a car driver, whose name is revealed to be Ronnie Pickering. ${ }^{4}$ In the recording, the car and moped come to a stop near one another and the two men swap insults and threats. The transcript starts as Pickering, in a line whose ambiguity soon takes center stage, asks the moped driver d'you know who I am? (line 1). This is a veiled threat: Ronnie Pickering was an amateur boxer, so knowing this amounts to being forewarned of the injuries he could inflict in a fight.

(4) RonniePickering_YouTube_participant-generated/UK 


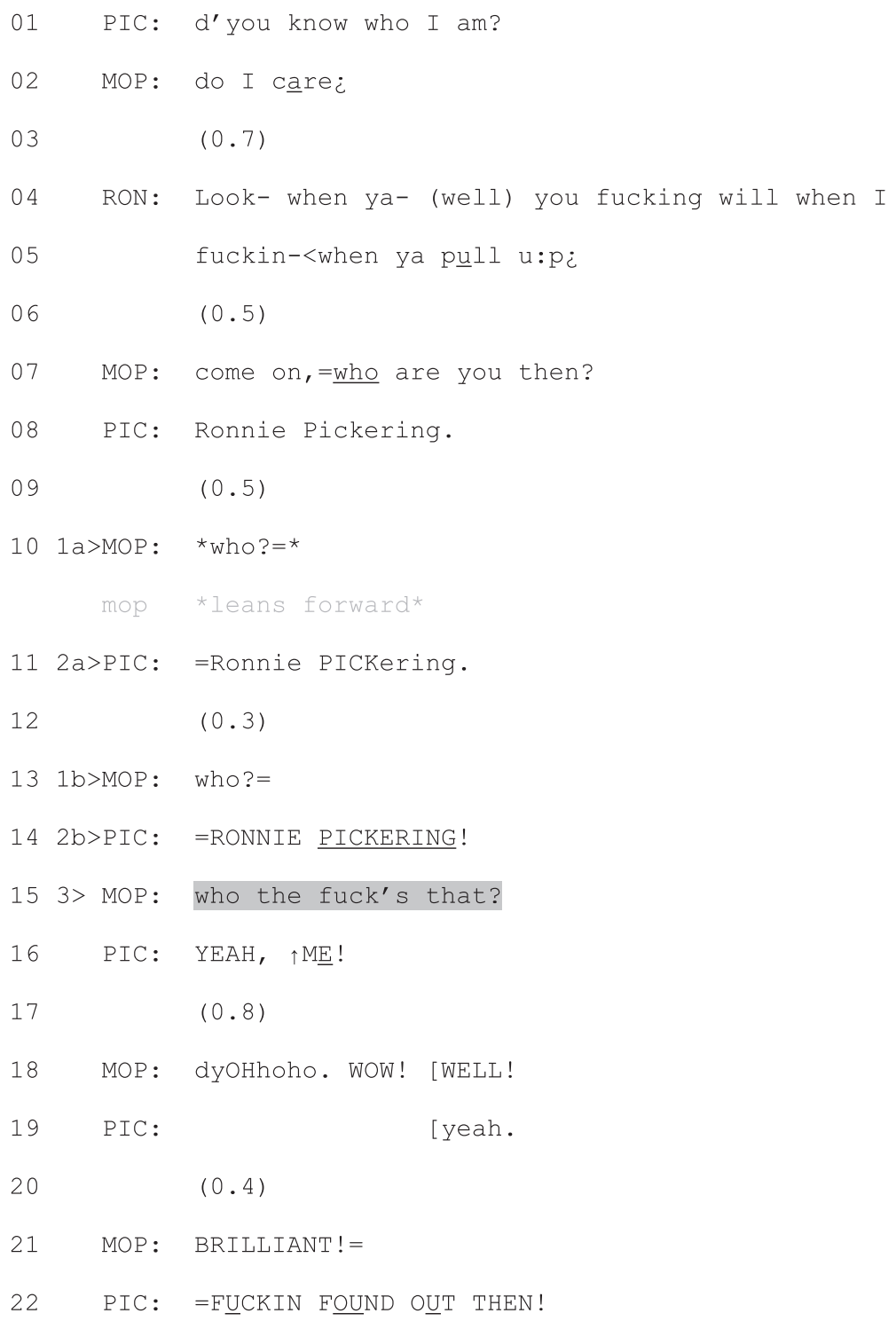

The moped driver initially dismisses Pickering's question (do I care?) but eventually takes the bait, asking who are you then? (line 7). Pickering responds with his full name (line 8). That is, he uses a recognitional reference form, which claims that his recipient should be able to recognize it (Sacks \& Schegloff, 1979). This is evidently poorly designed for his recipient, however. The moped driver responds by leaning forward (Rasmussen, 2014) and producing a category-specific repair initiator who? (Drew, 1997). These actions in Position 1a target Ronnie Pickering as inadequate, and oblige Pickering to clarify the import of that reference in next turn. In Position 2a, Pickering's repair solution is to repeat himself, only more loudly (line 11). This response treats the trouble as one of hearing, and treats the recipient as able to recover the reference if he could only hear it again. It also shows that Pickering understands Ronnie Pickering as altogether adequate as he produced it the first time and in need of no modification. However, the recognitional reference form remains unexplicated and thus inadequate. This occasions a second round of repair in Positions $1 \mathrm{~b}$ and $2 \mathrm{~b}$ : the moped driver again asks who? and Pickering again shouts his name with even greater intensity (lines 13-14). 
In this environment - after repair initiation has now twice failed to elicit an adequate repair solution-we see in Position 3 our practice of expletive insertion. The moped driver expands his repair initiation to produce who the fuck's that? (line 15). This is subsequently positioned relative to his prior repair initiations in lines 10 and 13. By reissuing it, he rejects Pickering's repair solutions and treats Ronnie Pickering not only as inadequate, but sanctionably so. Expletive insertion accomplishes sanctioning via the transgressive status of swearwords: the violation of one norm (against expletive use) claims a warrant for itself, and that warrant is found in the most proximal action (here, inadequate person reference). It is retrospectively treated as a violation (we return to this in the discussion).

Expletive insertion in a sequence-initiating action may thus occur within a three-part sequence. We elaborate on this sequential organization below, addressing next the difficulties that occasion actions in Position 1.

\subsection{Position 1 actions orient to interactional difficulties}

Sequence-initiating actions in Position 1 orient to various difficulties and provide for their resolution in next turn. At this point in the sequence, the problematic nature of the difficulty remains relatively unexposed ('relatively' compared to its exposure in Position 3). In Extract 4, the repair initiations made relevant a repair solution from Pickering that would rectify the infelicities of Ronnie Pickering. Although those infelicities violated normative expectations about recipient design, their status as violations remained latent. That is, Pickering was obligated only to correct the problems of his misdesigned turn, not account or apologize for having misdesigned it. The next case more clearly shows how actions in Position 1 provide for the resolution of some difficulty while leaving unexposed the violation it embodies. Five men (Speakers A through E) marvel at what has been identified as a 'UFO' — a bright light moving anomalously in the night sky. Speaker

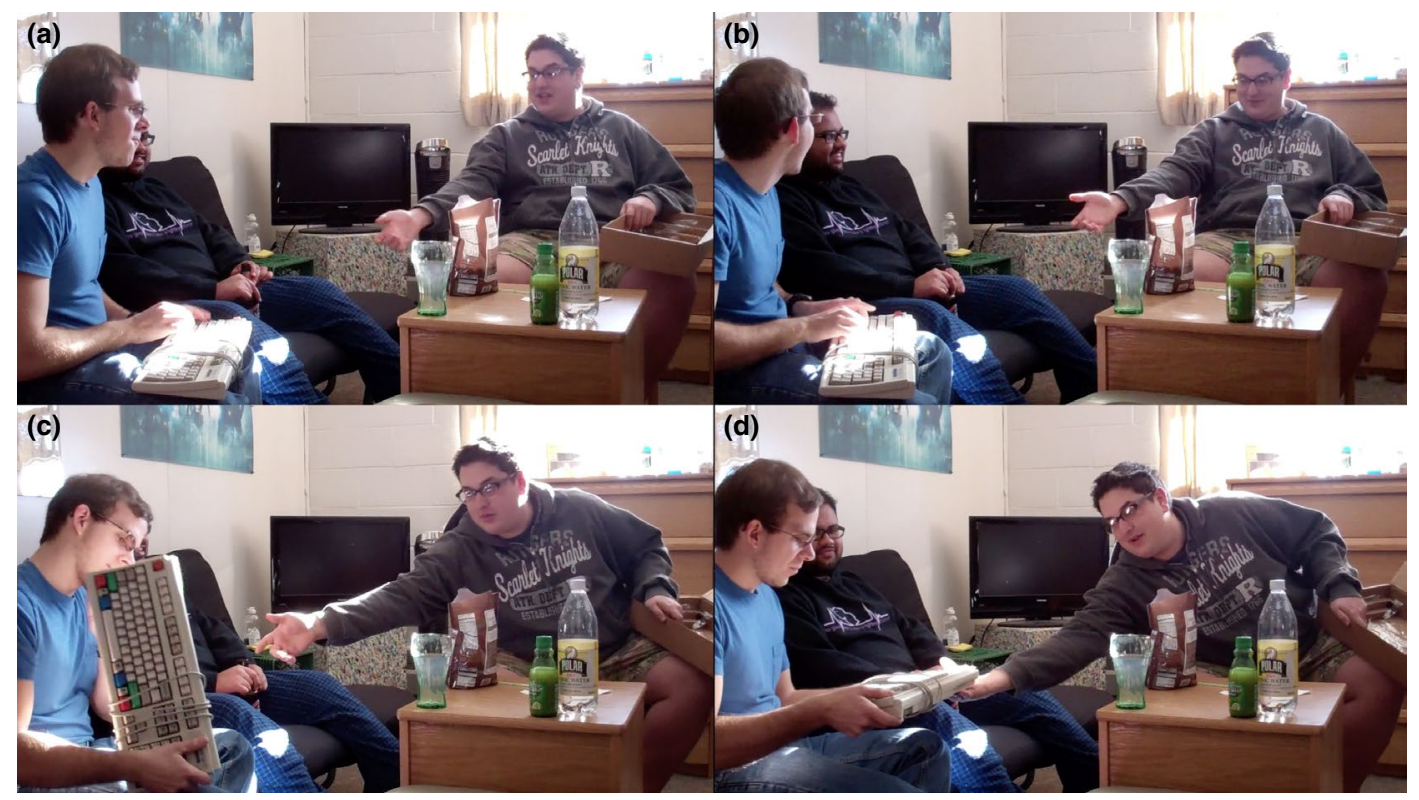

F I G URE 1 Left to right: Alan, Ben, and Caleb. Caleb's multiple attempts to retake his keyboard 
A jokingly identifies it as the eye of Mordor, referring to the fictional villain from Lord'a the Rings. This identification is recognizably nonserious, as seen in the responsive laughter from Speakers B and C. These participants are thus 'joking around', which another speaker later treats as a source of difficulty.

(5) 053_UFO_YouTube_participant-generated/US

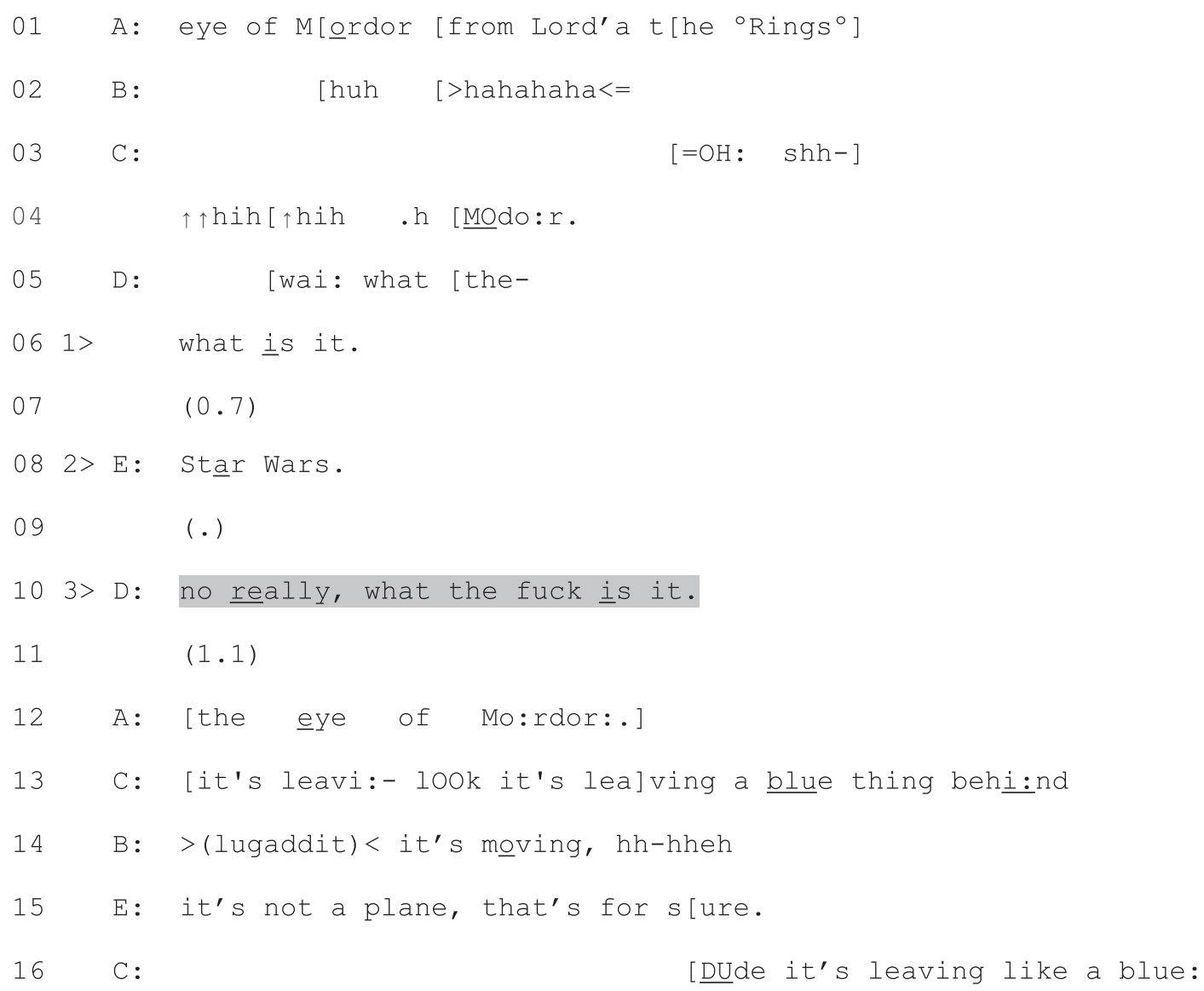

Speaker D displays a discrepant orientation to the others' joking activity. He enters with wai: what the- (line 5) directly after the prosodic peak of Speaker C's laughter ( $\uparrow \uparrow h i h$ ), which is perhaps the earliest possible point he could begin as next speaker (Jefferson, Sacks, \& Schegloff, 1977). This early turn-initiation indicates misalignment, as it intercepts further development of and thereby competes with 'joking around' (Lerner, 1996). Misalignment is also observed in his turn-initial wai:, a plea to arrest the ongoing course of action. He continues with the interrogatively formatted what the- (line 5) - presumably the start of what the fuck or what the fuck is it. However, he cuts

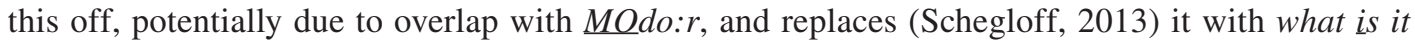
(line 6). This question resists the previous eye of Mordor characterization, and, through prosodic emphasis on $\underline{i} s$, invokes a contrast (cf. Raymond, 2017) between that joking characterization and a non-joking one. 
Speaker D thus orients to a discrepancy in seriousness while not making that discrepancy a sequentially implicative matter. The relevant response is a sincere characterization of the 'UFO'; this would realign the participants and the discrepancy would remain unexposed. This does not happen, however. Though Speaker D's question is designed for a serious answer, Speaker E gives a nonserious response, Star Wars (line 8). By giving another fictional reference, Speaker E continues 'joking around', disaligning with Speaker D. The inadequacy of Star Wars does not have an innocent basis, either. On the contrary, Star Wars is sanctionable because, from Speaker D's perspective, Speaker E did hear and understand his question. This amounts to willful and sanctionable noncooperation.

In Position 3, Speaker D explicitly rejects Speaker E's nonserious answer and reissues his question with expletive insertion: no really, what the fuck is it (line 10). With this, he pursues a serious response and sanctions Speaker E for his willful noncooperation. What is relevant in response to being sanctioned is acquiescence or resistance to the charge, among other possibilities (apology, account, etc.). Something of both of these choices is seen in Speaker E's response, it's not a plane, that's for sure (line 15). While this serious response realigns him with Speaker D, Speaker E bristles somewhat at being scolded. For one, it's not a plane is a shade uncooperative because it still leaves Speaker D's question unanswered (Raymond, 2003). Furthermore, that's for sure emphasizes the obviousness and unnecessariness of his observation.

This extract illustrates how actions in Position 1 manage various difficulties-not only incongruities in person reference but also discrepancies in seriousness. It also shows how orientations to these difficulties leave the problem relatively unexposed, allowing the recipient to identify and resolve the

problem themselves. ${ }^{5}$ So what remains buried in Position 1 is revealed in Position 3 through more 'explicit' orientations. We discuss this escalation in orientations next.

\subsection{Expletive insertion and escalation}

Actions in Position 3 can implement pursuits by obligating the recipient to produce some particular response that was not produced before. These actions are designed as upgraded versions of the Position 1 action; they have turn-constructional elements that display 'more' of some feature like explicitness, bluntness, consequentiality, etc. Their upgraded status works in tandem with their sequential positioning to establish a trajectory of escalation: relative to a Position 1 action, a Position 3 action is upgraded, which projects an even more upgraded Position 5 action, and so forth. We examine these aspects of escalation-turn-design and sequential positioning-through two examples below.

Extract 6 shows multiple pursuits to retake possession of an object, with each effort more upgraded than the last. Before this conversation among three friends (Alan, Ben, and Caleb), Caleb had purchased a vintage computer keyboard. He introduces it with have you seen my new keyboard and hands it to Alan for a closer look (data not shown). Caleb evidently expected Alan to briefly inspect and positively appraise his keyboard (see Hoey \& Kendrick, 2018), but instead Alan uses it as a prop in reenacting a humorous scene from the film Meet the Parents. This leads to some discord: Alan keeps the keyboard while Caleb over multiple pursuits undertakes to recover it.

(6) 086_Brianna1_3228_researcher-generated/US 
01 CAL: > have you seen my new keyboard?<

((lines omitted; CAL hands keyboard to ALA))

11 BEN: do you feel like you're typing on a typewriter? (0.2)*

ala >types slowly on keyboard---------------------- >*

12 ALA: no. e-eu- $d^{\prime}$ you remember uhm $+>$. nhh $<$

$\mathrm{cal}$

13

CAL: \#+it's wonder[ful is it not?]

ALA :

[ ${ }^{*}$ no. *no. ]<+do you remember in: (.) +

*raises hand*

cal textends open hand to ALA--->+retracts-------------->+

fig \#1a

15

ALA: Meet the Parents?

((lines omitted; ALA recounts funny story from movie))

24 BEN : hnhehheh+heh+\#heh [hehheh

25 1> CAL: [gimme my keyboard back.

$+\ldots$ textends open hand to ALA-->

fig

\#16

26

(1.0)

CAL: 'f you cn put a* price tag on that you* win.

ala

(1.1)

28

BEN: I can put a price tag [on it.

30

CAL :

[you know.

31 2> ALA:

[high or low. is it- is it like a

CAL :

$+(.)^{\circ}$ like is it* $\left[a^{\circ}\right.$

[

+leans toward ALA, arm fully outstretched--------------->

2>ala

*......... looks at keyboard's underside->

fig

\#1 C

34 1> CAL: =i-<give it to me. ((in 'serious' prosody))

35

$(0.3) *(0.6) *(0.3)$

ala $--->^{*} \ldots . . *$ transfers keyboard to CAL->>

36 3> CAL: gim+me back m\#y fucking key[board.

ALA :

[ I thought you were gonna have=

cal ---treceives/takes keyboard->>

fig \#1d

38 ALA: =a Dvorak keyboard.

39 CAL: no, I don't do Dvorak. 
After being handed the keyboard, Alan inspects it by slowly typing. His contact with it occasions the question do you feel like you're typing on a typewriter? (line 11). Alan responds no but continues with d'you remember uhm (line 12). This projects something like 'what it reminds me of' in contrast to 'what it feels like'. At this point, Caleb's makes his first move to retake his keyboard: he extends his arm toward Alan with a palm-up receptive handshape, a recognizable embodied request for object transfer (Figure 1a). While reaching, Caleb positively assesses his keyboard in declarative format with a tag question, it's wonderful is it not? (line 13), which projects agreement in next position. However, Alan resists Caleb's actions: he produces a rejection no no while holding his hand up, intercepting Caleb's reach (line 14). Caleb acquiesces by retracting his arm, as Alan proceeds to recount the scene from Meet the Parents (lines 14-15).

Alan reaches the climax of the telling by reenacting the typing actions of a movie character, which Ben appreciates with laughter (line 24). This brings the telling to possible completion, which Caleb orients to by demanding his keyboard be returned. He formats his demand, which occupies Position 1 of our sequence, as gimme my keyboard back (line 25) while reaching with his hand in receptive formation (Figure 1b). This is an upgraded version of his prior attempt, which was simply a reach plus the assessment it's wonderful is it not. It makes his demand explicit, puts on the record what is expected in response, and displays high entitlement to make such an order (Craven \& Potter, 2010). Again, however, Alan does not comply, but retains the keyboard in prolonging the telling's climax (lines 24-26).

In response to Alan's continued noncompliance, Caleb poses a challenge: if you can put a price tag on it you win (line 27). This 'guess the price' activity displaces Alan's telling and has as a possible outcome the return of his keyboard. This alternative tactic, however, is unsuccessful. Alan responds not by 'guessing the price' but by initiating a pre-second insert sequence (Schegloff, 2007), asking for a 'hint' as to whether the price is high or low (line 31). Furthermore, he delays returning the keyboard by examining its underside for potential indications of cost (Figure 1c). These actions constitute yet more noncompliance with Caleb's explicitly formulated and embodied request.

The exchange escalates into discord from this point. Caleb rejects Alan's solicitation of a 'hint' and reasserts his challenge (line 33). He produces this with 'annoyed' prosody (higher pitch, slightly quicker), auditorily indexing prior failures to retake the keyboard. He also significantly reconfigures his posture: Caleb leans over Ben's lap, fully extending his arm with his hand midway between a receptive and acquisitive formation (Figure 1c). This reconfiguration, in its substantial departure from Caleb's previous posture, makes object transfer relevant 'now'. The urgency of object transfer is further underscored by Caleb's reissued demand give it to me (line 34). The deictic pronoun it (i.e. the keyboard) makes this hearable as a subsequent demand, and his use of 'serious' voice quality (lower global pitch, falling terminal intonation) audibly marks this demand as graver or more consequential than the last.

Shortly after Caleb's demand, Alan starts to return the keyboard (line 35). As object transfer is underway, Caleb reissues his demand with expletive insertion: gimme back my fucking keyboard (line 36). This sanctions Alan for his repeated, willful noncompliance and terminates the following trajectory of escalation:

(i) reach (line 13)

(ii) reach + gimme my keyboard back (line 25)

(iii) extended reach + give it to me with 'serious' prosody (line 34)

(iv) extended reach + gimme back my fucking keyboard (line 36).

Each successive action responds to the recipient's uncooperative behavior with an upgraded action. Caleb's bodily conduct escalates from a simple reach to an extended one (Figure 1d), and his speech 
is upgraded with an explicit demand in 'serious' prosody and then with expletive insertion. Caleb displays increasing commitment to retaking his keyboard, with each successive turn more 'on record' than the last. The terminal positioning of his expletive insertion turn indicates the extremity of the practice, appearing after other methods failed to elicit the normatively expected response.

Escalation is constituted by turn-constructional methods for upgrading and by the sequential ordering of those methods. The availability of two versions of the 'same' action in Positions 1 and 3 permits a comparison of the two. The qualitative difference between these actions may then be used to extrapolate a hypothetical Position 5 action that is likely to be even further upgraded. Projection of this trajectory of action thus provides for the recognizability of escalation via the sequential positioning of comparable actions.

This process of projection and escalation is seen most clearly in the use of expletive insertion in violent interactions. Studies of violence have demonstrated the importance of examining the situated production of potentially violent interactions (Whitehead, Bowman, \& Raymond, 2018). We believe it is necessary to examine expletive insertion in violent interactions to understand how participants to escalating scenes of potential violence constitute their settings as such. In Extract 7, four men (Red, Cam, Black, and White) are approaching a Man and a Woman to intervene in an episode of intimate partner violence outside a shopping center. ${ }^{6}$ As they approach, the Man orders them to STAY OUT OF $I T$. Two interleaving sequences then emerge, each leading to expletive insertion (1-3a and $1-3 \mathrm{~b})$. We will focus on 1-3a and subsequent upgrades.

(7) 089_YouTube_assault_participant-generated/US

01

02

03

$041 \mathrm{a}>$

$052 a>1 b>M A N:$

$063 a>2 b>R E D:$

07

08

09

10

11

12

13

14

15

RED: ((intervening party approaches MAN and WOM))

MAN : [(STAY OUT OF IT.)

WOM: $[\mathrm{HE}(\quad)$ HIT ME : [ :

[WHÄt're you gonna do. $=$

$=$ STAY OUT OF IT.

what're you gonna fückin do.

stay the fuck out of it.=

RED: =what the fuck are you gonna do, bitch.

$(0.5)$

RED : $\quad \underline{H U H}$ ?

$(1.2)$

MAN: [stay the fuck out of it.

WHI : $\quad[(\quad)=$

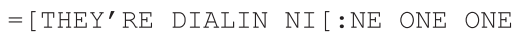

RED: $=[\underline{\text { ey }}$ call- ey $\quad[\underline{c a l l}$ the cops yeah.

The intervening party does not STAY OUT OF IT, but instead, Red provokes the Man with WHA $\underline{A} t^{\prime} r e$ you gonna do (line 4). This 'rhetorical' question in Position 1a is a counterthreat. While the format of the question makes relevant a 'what I will do' response, the action that the question embodies makes relevant backing down from the conflict. This works through the negative assertion (Koshik, 2003) 'you can/will 
do nothing', which implies capitulation. In Position 2a, the Man repeats STAY OUT OF IT. This is plainly uncooperative; it is not the conditionally relevant response to WHAt're you gonna do. The Man's belligerence provides for Red's expletive insertion turn what're you gonna fuckin' do (line 6), which is aimed at intimidating the Man and sanctioning him for his defiance.

Red's expletive insertion turn in Position 3a is an upgraded version his command in Position 1a. The difference between these turns in explicitness or aggression can be used to project an even more upgraded Position 5 action. And indeed, we observe this as the interaction continues. The Man remains belligerent (stay the fuck out of it; line 7), which warrants another attempt to secure compliance. In Position 5, Red reissues his action as what the fuck are you gonna do, further upgrading it with a derogatory and misogynistic address term bịtch (see Lerner, 2003) and, following a gap, a hostile provocation for response $\underline{H U H}$ ? (lines 8-10).

The participants are clearly in conflict: each one's demand fails to secure compliance from the other, as each sequence-initiation is subverted through the (re)initiation of a competing one. Consequently, neither sequence gets off the ground. The participants have evidently reached the limits of the adjacency pair organization as a method for coordinating social action. This is because the adjacency pair organization requires a base level of cooperation-that following a sequence-initiating action there appears a response selected from a restricted range of relevant actions (Schegloff \& Sacks, 1973). Here, there are no relevant responses, only a series of initiations and escalated counter initiations (cf. Schegloff, 2007). In such a situation, what can participants do? What other resources are available to secure compliance? As we have suggested, a trajectory of escalation projects an even more upgraded subsequent action. In this case, a more upgraded action appears as the transcript concludes. The intervening party resorts to DIALIN NINE ONE ONE and calling the cops (lines 14-15). So, given the inadequacy of conducting interaction through adjacency pairs, Red fulfills his implied threat by appealing to an entity with the institutionalized right to enforce certain norms, including through violence.

Expletive insertion thus contributes to the process of escalation. Extract 6 shows that the practice is paradigmatically related to other methods for pursuit, and stands as a relatively 'extreme' alternative. Furthermore, as shown in Extract 7, its use permits a comparison to be made between the pursuit in Position 3 and the prior action in Position 1. Consequently, this projects an even more extreme action in Position 5.

\section{5 | Sequential indexicality}

We have described how expletive insertion works in subsequently positioned actions-how it is predicated on some interactional trouble, how that trouble is managed first through some effort to resolve it, and then through pursuit and escalation. This fundamental organization provides for the mundane recognizability of expletive insertion in initially positioned actions (Extracts 3-4). Expletive insertion in initial position invokes the organization of the practice in subsequent position (i.e. a trouble, an effort to resolve it, pursuit, and escalation) through a kind of sequential indexicality. Certain forms are associated with certain sequential environments, the features of each reflexively pointing to the other. Participants can rely on this association in using 'mismatches' between form and environment. To return to our previous cases, we know that Kimmy first tried to find her bag before asking aloud where the fuck is my little firestarting bag (Extract 4). So through her question, she indexes the fact that her search had been unsuccessful. And with THE FUCK OUTTA HERE RIGHT NOW (Extract 3 ), expletive insertion lets the dad exhibits the situation itself as already extreme and escalated. $\mathrm{He}$ 
may be seen specifically not making a first effort to banish his daughter, and instead leaping directly to an escalated position. ${ }^{7}$

\section{5 | DISCUSSION}

We have described a three-turn sequence that involves inserting an expletive like the fuck into a turn. A sequence-initiating action in Position 1 orients to some difficulty between participants and provides for its resolution in next turn. However, it receives in Position 2 an uncooperative or inappropriate response. This occasions in Position 3 a pursuit with expletive insertion, which sanctions the response and may pursue what was relevant, but not given, in Position 2. This sequence embodies a normative ordering whereby participants first manage interactional difficulties through relatively tacit procedures, and then given the failure of those, through more explicit and escalated ones. We suggest that this sequential organization is invoked-that features of pursuit and escalation are sequentially indexed-when expletive insertion is used in initially positioned actions. We discuss these findings with respect to the 'fit' between expletive insertion and sanctioning, the organization of pursuits, and swearing studies more generally.

\subsection{Fit between the practice and the action}

How does expletive insertion in a sequence-initiating action (the practice) accomplish sanctioning (the action; Schegloff, 1996)? First, the normative organization of adjacency pairs provides for seeing violations of it. Using adjacency pairs commits participants to, among other things, providing a conditionally relevant response after the recognizable production of a sequence-initiating action, where the absence of that response is a noticeable and sanctionable occurrence (Schegloff \& Sacks, 1973). Position 1 actions are designed to address some difficulty by implicating a response that could promote its resolution. This background expectancy provides for seeing Position 2 actions as inappropriate or uncooperative responses - as violations of a norm.

Second, after an inadequate response, sanctioning is among the range of relevant next actions. The sequential environment after a response is a systematic locus for evaluating the adequacy of that response. Given a recognizably inadequate response, speakers may pursue a more adequate one. Designing this pursuit involves a diagnosis of just how the response was inadequate. That is, for a pursuit to elicit the sought-after response, a speaker needs some analysis of whatever it was that occasioned the pursuit in the first place. ${ }^{8}$ They may diagnose the inadequacy as rooted in mishearing, belligerence, ignorance, etc. The diagnosis relevant for our purposes is that the response is inadequate because of some sanctionable failure by the recipient. Where the recipient is found to have failed in this way, then sanctioning becomes a relevant possibility.

And third, sanctioning may be accomplished through swearing because their use is optional and therefore seeable as used 'for cause'. Expletive insertion designedly violates normative restrictions on swearing but shows that violation as not unwarranted. Rather, the violation tacitly claims a warrant for itself - a warrant which, by the principle of adjacency (Sacks, 1987), may be located in the just prior action. The speaker's transgression is retrospectively linked to the recipient's transgression (as a 'retro sequence'; Schegloff, 2007), producing a tit-for-tat violation of social norms. A second violation (expletive insertion in subsequent position), in its conspicuousness, incriminates a first, rendering it as a violation. By treating expletive use as provoked by an earlier violation, sanctioning is accomplished. 


\subsection{Expletive insertion among methods for pursuit}

There are a range of practices for treating a response as inadequate, inappropriate, etc. These include various types of repair initiation and various redoings of the sequence-initiating action (e.g. Bolden, Mandelbaum, \& Wilkinson, 2012; Davidson, 1984; Persson, 2015; Romaniuk, 2013; Sikveland, 2019). Given this assortment of methods, speakers must select among them, which, in turn, implicates principles conditioning their selection. We suggest that the selection of one of these practices over others orients to matters of responsibility and blame for the inadequacy of the response. With expletive insertion, a speaker explicitly orients to the recipient as sanctionably blameworthy for the inadequacy. We can compare it to other methods for pursuit.

After a recognizably inadequate response, the matter of responsibility is a live issue for participants (cf. Robinson, 2006). As suggested, participants seek to diagnose the inadequacy of the response as a practical matter. Take, for example, oh I meant-prefacing in third position self-repair (Schegloff, 1992b). Oh I meant-prefacing treats the response as inadequate because it revealed the recipient's misapprehension of the speaker's initiating action. However, while the recipient is indeed accountable as having misunderstood, they are not culpable for that misunderstanding. Rather, the speaker treats their own initiating action as poorly recipient-designed (i.e. open to type of misapprehension shown by the recipient). The problem, then, is the speaker's turn, which makes them the responsible party.

There are also devices to avoid apportioning blame for an inadequate response. After a noticeably absent response, a speaker may pursue a response with a self-repeat (e.g. Sikveland, 2019). A self-repeat without any prosodic modification or linguistic reformatting can avoid an attribution of fault. While it treats the absence of a response as inadequate, and while it treats the recipient as still obligated to respond, it withholds imputing any blame to them. At the same time, the speaker treats their prior sequence-initiating action as needing no repair, and thereby avoids accepting any blame for how it was designed.

By contrast, with expletive insertion the speaker does not treat their own prior turn as inadequate (as with oh I meant third position self-repair), nor do they minimize the attribution of fault (as with verbatim self-repeats). Rather, reissuing the sequence-initiating action with expletive insertion explicitly orients to the recipient's transgression and to their responsibility for it. The recipient is culpable for the problem that engendered the pursuit and therefore is deserving of sanction.

Speakers thus have devices to apportion responsibility and blame in different ways when accounting for an inadequate response. This is one way to arrive at lay characterizations of people as 'belligerent', 'long-suffering', 'indulgent', 'testy', and so forth.

\subsection{CA and swearing studies}

This paper builds on prior work on swearing by specifying how a turn-constructional operation in a particular sequential environment recurrently implements a recognizable social action. Instead glossing what swearing does (show negative attitude, mark in-group membership, etc.), we have situated each case in the course of action to which it contributed and from which it gained its intelligibility. And instead of presuming the relevance of contextual features like gender or formality, we have emphasized the sequential context as participants' primary resource for finding and producing meaningful action (Schegloff, 1992a). Our analyses are thus accountable to the features of interaction that are demonstrably relevant for participants. 
Our analysis extends CA research on swearing by analyzing a single linguistic practice and demonstrating that the tools of CA can capture orderly aspects of profanity. Other practices amenable to sequential analysis await systematic investigation, for example, expletive insertion in responses to polar questions (fuck yeah). More broadly, the principle of sequentiality (Schegloff, 2007) allows analysts to isolate swearing in the weave of interaction. To the extent that swearing is conventionally connected to emotion, one strength of CA is that it can technically specify 'places for' displays of emotion. We have described one such sequential environment that recurrently hosts something akin to frustration or vexation. Such descriptions of contexts where affective displays are relevant also offer an empirically grounded way to see where and that emotions are 'suppressed', 'sudden', 'unprovoked', etc.

We offer our account as distinct from but not in opposition to studies of swearing that center features like gender. Indeed, a CA account should enrich others, such as those based on indexicality (e.g. Ochs, 1992). As we have shown, expletive insertion has a first-order indexical relationship to stances of escalation, alongside which we might include threat, frustration, obduracy, and the like. Such stances, as mediated over time by language ideologies, may stabilize their indexical associations with identities, personas, and styles (Jaffe, 2009). To the extent that stances of escalation index masculinity, our account grounds an analysis of social categories in the sequentially situated details of action. Additionally, this article contributes to sociolinguistics the general notion of sequential indexicality, which operates at the level of action and stance. Participants' use of a particular form can sequentially index the environment that form tends to appear in and thereby invoke features of that environment. In our analysis, the use of expletive insertion in initial position sequentially indexes its occurrence in a subsequent position and the escalation implied thereby. In this way, they may position themselves as 'already escalated'.

\section{ACKNOWLEDGEMENTS}

A previous version of this paper was presented in 2016 at the 15th Conference of the International Pragmatics Association in Belfast, Northern Ireland. We extend our thanks to Galina Bolden and Rebecca Clift for permitting use of their data, and to Gertie Hoymann, who contributed to early stages of data collection and exploration.

\section{AUTHOR CONTRIBUTIONS}

KHK initiated and coordinated the project. EMH wrote the paper with input from KHK. All the co-authors contributed to data collection, exploration, transcription, and development of the initial analysis. EMH, PH, and WLS contributed to the literature review.

\section{ORCID}

Elliott M. Hoey (D) https://orcid.org/0000-0002-3220-8119

\section{ENDNOTES}

${ }^{1}$ Transcription of audible conduct follows Jefferson (2004). Transcription of visible conduct follows Mondada (2018). Sites of particular analytic interest are highlighted.

${ }^{2}$ Other languages in the data were Dutch, Italian, Japanese, Punjab, Spanish, and $\neq \bar{A}$ khoe Haillom. Of these, the practice only appeared in Italian. While we make no claims about the typological distribution of the practice, we note that similar constructions are attested in French, Greek, Hebrew, Hungarian, Japanese, Korean, Malagasy, Russian, Spanish, and Tsez (Dikken \& Giannakidou, 2002; Polinsky, 2007).

3 Though this makes our sample nonrandom, in keeping with our methodological commitments, we are not necessarily interested in claims of statistical generality. Instead, the generalizability of our findings are of a socially robust sortthat is, members, even those who do not swear in our data, recognize and orient to the practice as we have described 
it. After finding that expletive insertion was associated with situations of conflict and misalignment, we were then prompted to verify this analysis with other data. The eight cases we found strengthen this association.

4 This transcript shows Ronnie Pickering's real name given his public notoriety. Many UK news sources covered the massively viral video in 2015. He continues to be newsworthy to this day, most recently in January 2020 in the Mirror, 'Viral hit Ronnie Pickering pictured casually sipping pint at pub crash scene' (Mutch \& Randall, 2020).

5 Structurally this ordering resembles the preference for self- over other-initiated repair (Schegloff et al., 1977) and for self-remediation over assistance (Kendrick, 2017).

${ }^{6}$ Though the transcript does not depict any violence, readers may be justifiably sensitive to the fact that it is nevertheless predicated on violence against women. A warning is thus in order. We do not show this example flippantly as 'just another piece of data'. Rather, what emerged over the course of our analysis was a strong connection between expletive insertion, escalation, and (potentially) violent confrontations (e.g. Extract 4). The centrality of these features to the practice warranted inclusion of this example.

7 This argument parallels Schegloff's (1996) distinction between 'locally initial' and 'locally subsequent' positions when referring to third parties. 'Locally initial' captures the conversational regularity that when someone is mentioned for the first time, the reference form is usually a name (Nancy) or noun phrase (your sister). 'Locally subsequent' captures the complementary regularity: that when someone is mentioned a subsequent time, a pronoun is usually used (she). However, mismatches are possible; a locally subsequent form can appear in locally initial position and vice versa. Such mismatches are recognizably done 'for cause'. For instance, using they without first establishing who they are indexes the features of its typical environment (locally subsequent position). This can claim that they were previously in focus, perhaps in a prior conversation, and that their relevance continues to the present moment (Kitzinger, Shaw, \& Toerien, 2012).

8 This resembles other-initiated repair sequences (Schegloff et al., 1977). Other-initiated repair is predicated on some trouble source, the nature of which may or may not be fully explicit. To resolve the trouble, the speaker of the trouble source needs a diagnosis of the trouble (i.e. in hearing, speaking, and/or understanding). This diagnosis will be built into the design of the repair solution and if it is correct then the trouble is resolved.

\section{REFERENCES}

Allan, K. (Ed.). (2018). The Oxford handbook of taboo words and language. Oxford, UK: Oxford University Press.

Anderson, L. G., \& Trudgill, P. (2007). Swearing. In L. Monaghan \& J. Goodman (Eds.), A cultural approach to interpersonal communication (pp. 195-199). Blackwell.

Bolden, G. B., Mandelbaum, J., \& Wilkinson, S. (2012). Pursuing a response by repairing an indexical reference. Research on Language \& Social Interaction, 45(2), 137-155. https://doi.org/10.1080/08351813.2012.673380

Bopp, T. (1971). On fucking (well). A study of some quasi-performative expressions. In A. M. Zwicky, P. H. Salus, R. I. Binnick, \& A. L. Vanek (Eds.), Studies out of left field: Defamatory essays presented to James D. McCawley (pp. 61-71). Linguistic Research.

Butler, C. W., \& Fitzgerald, R. (2011). "My f***ing personality": Swearing as slips and gaffes in live television broadcasts. Text \& Talk, 31(5), 525-551. https://doi.org/10.1515/text.2011.026

Christie, C. (2013). The relevance of taboo language: An analysis of the indexical values of swearwords. Journal of Pragmatics, 58, 152-169. https://doi.org/10.1016/j.pragma.2013.06.009

Craven, A., \& Potter, J. (2010). Directives: Entitlement and contingency in action. Discourse Studies, 12(4), 419-442. https://doi.org/10.1177/1461445610370126

Davidson, J. (1984). Subsequent versions of invitations, offers, requests, and proposals dealing with potential or actual rejection. In J. M. Atkinson \& J. Heritage (Eds.), Structures of social action (pp. 102-128). Cambridge University Press.

Dikken, M. D., \& Giannakidou, A. (2002). From hell to polarity: "Aggressively non-D-linked" wh-phrases as polarity items. Linguistic Inquiry, 33(1), 31-61.

Drew, P. (1997). 'Open' class repair initiators in response to sequential sources of troubles in conversation. Journal of Pragmatics, 28(1), 69-101. https://doi.org/10.1016/S0378-2166(97)89759-7

Drew, P., \& Kendrick, K. H. (2018). Searching for trouble: Recruiting assistance through embodied action. Social Interaction Video-Based Studies of Human Sociality, 1(1). 
Dynel, M. (2012). Swearing methodologically: The (im) politeness of expletives in anonymous commentaries on Youtube. Journal of English Studies, 10, 25-50. https://doi.org/10.18172/jes.179

Garfinkel, H. (1967). Studies in ethnomethodology. Englewood Clifs, NJ: Prentice-Hall.

Garfinkel, H., \& Sacks, H. (1970). On formal structures of practical actions. In J. D. McKinney \& E. A. Tiryakian (Eds.), Theoretical Sociology (pp. 337-366). New York, NY: Appleton-Century Crofts.

Goffman, E. (1978). Response cries. Language, 54(4), 787-815. https://doi.org/10.2307/413235

Heritage, J. (1984). Garfinkel and ethnomethodology. Cambridge: Polity Press.

Heritage, J., Raymond, C. W., \& Drew, P. (2019). Constructing apologies: Reflexive relationships between apologies and offenses. Journal of Pragmatics, 142, 185-200. https://doi.org/10.1016/j.pragma.2019.01.001

Hoeksema, J., \& Napoli, D. J. (2008). Just for the hell of it: A comparison of two taboo-term constructions. Journal of Linguistics, 44(2), 347-378. https://doi.org/10.1017/S002222670800515X

Hoey, E. M., \& Kendrick, K. H. (2018). Conversation analysis. In A. M. B. de Groot \& P. Hagoort (Eds.), Research methods in psycholinguistics and the neurobiology of language: A practical guide (pp. 151-173). Wiley and Sons.

Jaffe, A. (Ed.). (2009). Stance: Sociolinguistic perspectives. Oxford: Oxford University Press.

Jay, T. (2009). The utility and ubiquity of taboo words. Perspectives on Psychological Science, 4(2), 153-161. https:// doi.org/10.1111/j.1745-6924.2009.01115.x

Jay, T., \& Janschewitz, K. (2008). The Pragmatics Of Swearing. Journal of Politeness Research, 4, 267-288. https://doi. org/10.1515/JPLR.2008.013

Jefferson, G. (1985). An exercise in the transcription and analysis of laughter. In T. A. van Dijk (Ed.), Handbook of discourse analysis vol. III (pp. 25-34). Academic Press.

Jefferson, G. (2004). Glossary of transcript symbols with an introduction. In G. H. Lerner (Ed.), Conversation analysis: Studies from the first generation (pp. 13-34). John Benjamins Publishing.

Jefferson, G., Sacks, H., \& Schegloff, E. (1977). Preliminary notes on the sequential organization of laughter. Pragmatics Microfiche, 1, A2-D9.

Jefferson, G., Sacks, H., \& Schegloff, E. A. (1987). Notes on laughter in the pursuit of intimacy. In G. Button \& J. Lee (Eds.), Talk and social organization (pp. 152-205). Multilingual Matters.

Kendrick, K. H. (2017). The preference for self-remediation over assistance in interaction. Paper presented at the 15th Annual International Pragmatics Association Conference. Belfast, U.K. 2017-07-17.

Kim, H. R. S. (2013). Retroactive indexing of relevance: The use of well in third position. Research on Language \& Social Interaction, 46(2), 125-143.

Korobov, N., \& Laplante, J. (2013). Using improprieties to pursue intimacy in speed-dating interactions. Studies in Media and Communication, 1(1), 15-33. https://doi.org/10.11114/smc.v1i1.49

Koshik, I. (2003). Wh-questions used as challenges. Discourse Studies, 5(1), 51-77. https://doi.org/10.1177/14614 456030050010301

Lerner, G. H. (1996). On the semi-permeable character of grammatical units in conversation: Conditional entry into the turn space of another speaker. In E. Ochs, E. A. Schegloff, \& S. A. Thompson (Eds.), Interaction and grammar (pp. 238-276). Cambridge University Press.

Lerner, G. H. (2003). Selecting next speaker: The context-sensitive operation of a context-free organization. Language in Society, 32(2), 177-201.

Lerner, G. H. (2013). On the place of hesitating in delicate formulations. In M. Hayashi, G. Raymond, \& J. Sidnell (Eds.), Conversational repair and human understanding (pp. 95-134). Cambridge University Press.

Ljung, M. (2011). Swearing: A cross-cultural linguistic study. London, UK: Palgrave MacMillan.

Mackenzie, J. L. (2019). The syntax of an emotional expletive in English. In J. Lachlan Mackenzie \& L. Alba-Juez (Eds.), Emotion in discourse (pp. 55-86). John Benjamins Publishing.

Majid, A. (2012). Current emotion research in the language sciences. Emotion Review, 4(4), 432-443. https://doi. org/10.1177/1754073912445827

McEnery, A. (2006). Swearing in English. London, UK: Routledge.

McEnery, A., \& Love, R. (2018). Bad language. In J. Culpeper, F. Katamba, P. Kerswill, R. Wodak, \& T. McEnery (Eds.), English language: Description, variation and context. Palgrave.

Mondada, L. (2018). Multiple temporalities of language and body in interaction: Challenges for transcribing multimodality. Research on Language and Social Interaction, 51(1), 85-106. https://doi.org/10.1080/08351813.2018.1413878

Mutch, M., \& Randall, L. (2020). Viral hit Ronnie Pickering pictured casually sipping pint at pub crash scene. Mirror. Retrieved from https://www.mirror.co.uk/news/uk-news/viral-hit-ronnie-pickering-pictured-21304229 
Napoli, D. J., \& Hoeksema, J. (2009). The grammatical versatility of taboo terms. Studies in Language, 33(3), $612-643$. https://doi.org/10.1075/s1.33.3.04nap

Ochs, E. (1992). Indexing gender. In A. Duranti \& C. Goodwin (Eds.), Rethinking context (pp. 335-358). Cambridge University Press.

Persson, R. (2015). Indexing one's own previous action as inadequate: On $a$-prefaced repeats as receipt tokens in French talk-in-interaction. Language in Society, 44(4), 497-524.

Pesetsky, D. (1987). Wh-in-situ: Movement and unselective binding. The Representation of (in) Definiteness, 98, 98-129.

Polinsky, M. (2007). What on earth: Non-referential interrogatives. In N. Hedberg \& R. Zacharski (Eds.), The grammar-pragmatics interface (pp. 245-262). John Benjamins Publishing.

Pomerantz, A., \& Mandelbaum, J. (2005). A conversation analytic approach to relationships: Their relevance for interactional conduct. In K. Fitch \& R. E. Sanders (Eds.), Handbook of language and social interaction (pp. 149-171). Lawrence Erlbaum.

Rasmussen, G. (2014). Inclined to better understanding-The coordination of talk and 'leaning forward' in doing repair. Journal of Pragmatics, 65, 30-45. https://doi.org/10.1016/j.pragma.2013.10.001

Raymond, C. W. (2017). Indexing a contrast: The do-construction in English conversation. Journal of Pragmatics, 118 , 22-37. https://doi.org/10.1016/j.pragma.2017.07.004

Raymond, G. (2003). Grammar and social organization: Yes/no interrogatives and the structure of responding. American Sociological Review, 68(6), 939-967. https://doi.org/10.2307/1519752

Robinson, J. D. (2006). Managing trouble responsibility and relationships during conversational repair. Communication Monographs, 73(2), 137-161. https://doi.org/10.1080/03637750600581206

Romaniuk, T. (2013). Pursuing answers to questions in broadcast journalism. Research on Language \& Social Interaction, 46(2), 144-164. https://doi.org/10.1080/08351813.2013.780339

Sacks, H. (1987). On the preferences for agreement and contiguity in sequences in conversation. In G. Button \& J. R. E. Lee (Eds.), Talk and social organisation (pp. 54-69). Multilingual Matters.

Sacks, H., \& Schegloff, E. A. (1979). Two preferences in the organization of reference to persons in conversation and their interaction. In G. Psathas (Ed.), Everyday language: Studies in ethnomethodology (pp. 15-21). Irvington Publishers.

Schegloff, E. A. (1992a). In another context. In A. Duranti \& C. Goodwin (Eds.), Rethinking context: Language as an interactive phenomenon (pp. 191-228). Cambridge University Press.

Schegloff, E. A. (1992b). Repair after next turn: The last structurally provided defense of intersubjectivity in conversation. American Journal of Sociology, 97(5), 1295-1345. https://doi.org/10.1086/229903

Schegloff, E. A. (1995). Discourse as an interactional achievement III: The omnirelevance of action. Research on Language and Social Interaction, 28(3), 185-211. https://doi.org/10.1207/s15327973rlsi2803_2

Schegloff, E. A. (1996). Confirming allusions: Toward an empirical account of action. American Journal of Sociology, 102(1), 161-216. https://doi.org/10.1086/230911

Schegloff, E. A. (2003). The surfacing of the suppressed. In P. J. Glenn, C. D. LeBaron, \& J. Mandelbaum (eds.), Studies in Language and Social Interaction: In Honor of Robert Hopper (pp. 241-262). Mahwah, NJ: Lawrence Erlbaum Associates.

Schegloff, E. A. (2007). Sequence organization in interaction. Cambridge, UK: Cambridge University Press.

Schegloff, E. A. (2013). Ten operations in self-initiated, same-turn repair. In M. Hayashi, G. Raymond, \& J. Sidnell (Eds.), Conversational repair and human understanding (pp. 41-70). Cambridge University Press.

Schegloff, E. A., Jefferson, G., \& Sacks, H. (1977). The preference for self-correction in the organization of repair in conversation. Language, 53(2), 361-382.

Schegloff, E. A., \& Sacks, H. (1973). Opening up closings. Semiotica, 8(4), 289-327. https://doi.org/10.1515/ semi.1973.8.4.289

Sidnell, J., \& Stivers, T. (Eds.). (2013). The handbook of conversation analysis. Malden: Wiley-Blackwell.

Sikveland, R. O. (2019). Failed summons: Phonetic features of persistence and intensification in crisis negotiation. Journal of Pragmatics, 150, 167-179. https://doi.org/10.1016/j.pragma.2019.01.023

Stapleton, K. (2010). Swearing. In M. A. Locher \& S. L. Graham (Eds.), Interpersonal pragmatics (pp. 289-306). De Gruyter.

Wajnryb, R. (2005). Language most foul. Crows Nest, NSW: Allen and Unwin. 
Whitehead, K. A., Bowman, B., \& Raymond, G. (2018). "Risk factors" in action: The situated constitution of "risk" in violent interactions. Psychology of Violence, 8(3), 329-338. https://doi.org/10.1037/vio0000182

How to cite this article: Hoey EM, Hömke P, Löfgren E, Neumann T, Schuerman WL, Kendrick KH. Using expletive insertion to pursue and sanction in interaction. $J$ Sociolinguistics. 2021;25:3-25. https://doi.org/10.1111/josl.12439 